Session 1532

\title{
A Comprehensive Laboratory Design Project for Teaching Advanced Circuit Analysis
}

\author{
Samara Firebaugh, Brian Jenkins, and John Ciezki \\ United States Naval Academy
}

\begin{abstract}
This paper describes a design project for sophomores learning advanced circuit concepts related to frequency response. The objective of the design project is to design a row or column detector for a touch-tone keypad. The project is conducted in small groups of two to three students. Each group designs and builds a detector for a single row that will produce a logical "high" when a button from that row or column is pressed and a logical "low" otherwise. The project is focused on the design of the filter stages, using both Laplace analysis and convolution to demonstrate an understanding of the frequency response of circuits. The students must not only design, build and test their filters, but also model and analyze the circuit using MATLAB. Elements of the project, such as the design of an individual filter stage or the use of MATLAB to perform convolution, are integrated into laboratory exercises during the semester. The digital portion of the design connects this course with the introductory digital logic course that the students take concurrently. This project also introduces students to peak detectors and comparators, which relates the course to the electronics course the students will take in the following semester.
\end{abstract}

Introduction

Surveys of undergraduate perceptions about electrical engineering have indicated a conflict between student expectations for the subject and their undergraduate experience. While they anticipated studying a practical subject with some necessary background theory, they perceive their undergraduate experience as being highly abstract with little emphasis on application, particularly before the senior year. This problem is cited as one of the possible causes for high attrition rates from the engineering fields. ${ }^{1}$ It is essential, therefore, to emphasize practical applications at every level. A large portion of the second semester of the Naval Academy's introductory electrical engineering course for sophomores focuses on frequency response concepts such as resonance, filters, transfer functions and the application of Laplace analysis and convolution. These concepts are abstract and mathematically intensive, so illustration of their practical application is particularly important.

One practical application of these concepts with which the students can readily identify is the touch-tone telephone. A telephone keypad consists of 12 buttons arranged in 4 rows and 3 columns (Figure 1). Pressing a button generates two sinusoids that correspond to the row and column of the button. A touchtone telephone decoder separates and identifies the two frequencies through a combination of filters. ${ }^{2}$ We have developed a multi-part design laboratory exercise based on this system that involves design, analysis, implementation and testing. The end 
product for each student group is a detector circuit for a single row that will produce a logical "high" when a button from that row is pressed and a logical "low" otherwise.

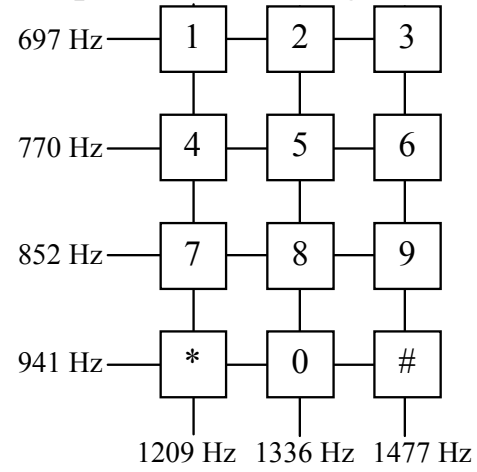

Figure 1: Touch-tone button signal frequencies (Adapted from C. K. Alexander and M. N. O. Sadiku, p. 659. $)^{2}$

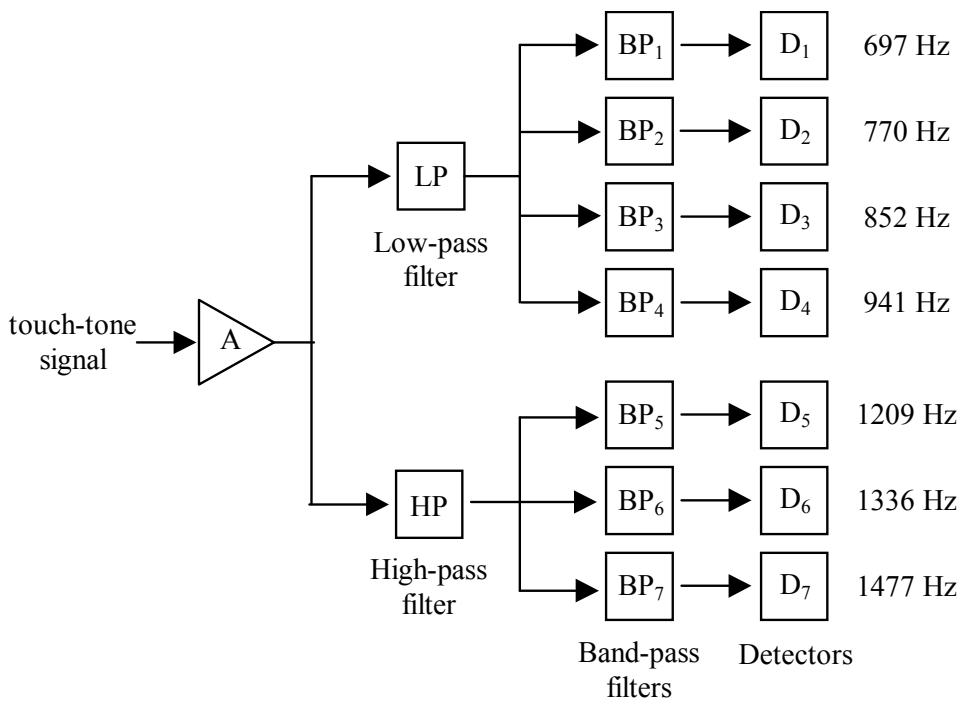

Figure 2: Block diagram for tone decoder (Adapted from C. K. Alexander and M. N. O. Sadiku, p. 659. $)^{2}$

\section{Project Description}

Figure 2 shows a block diagram for a touch-tone telephone decoder. Each student group had to implement only a portion of this, corresponding to a row detector (Figure 3). In particular, the students focused on the design of the low-pass (LP) and band-pass (BP) filters. The specifications for the design of these filters are shown in Table I.

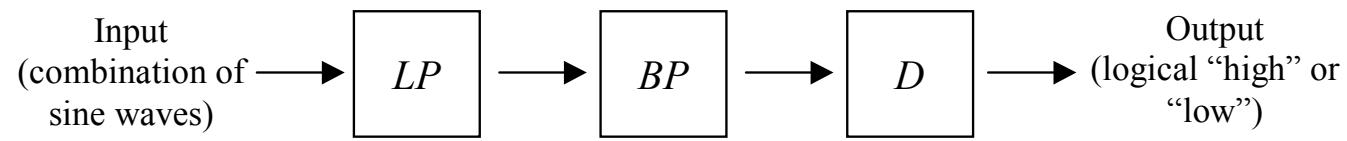

Figure 3: Block diagram for a row detector (LP: low-pass filter, BP: band-pass filter, D: detector)

The students were guided to implement active filters using 741 operational amplifiers. For each filter they could choose to pursue either a Butterworth filter (Figure 4) or a cascaded filter 
design. After determining the desired frequency response for each filter stage and choosing component values, the students constructed and tested each stage. For the simulation portion of the assignment, the students had to first determine for each filter stage the transfer function and the corresponding impulse response using an inverse Laplace transform. Then the students used convolution in MATLAB to determine the response of their filters to the signal produced by dialing the area code for their hometown.

Table I: Specifications for filter design

\begin{tabular}{|ll||ll|}
\hline Low-pass filter: & & Band-pass filter: & \\
\hline \hline Filter roll-off: & $40 \mathrm{~dB} /$ decade & Passband gain: & $0 \mathrm{~dB}+/-0.5 \mathrm{~dB}$ \\
\hline Passband gain: & $0 \mathrm{db}+/-0.5 \mathrm{~dB}$ & $\mathrm{Q}:$ & $>10$ \\
\hline $3 \mathrm{~dB}$ frequency: & $941+5 \%$ & Centerband frequency: & $697 \mathrm{~Hz}$ (for 123 row) \\
& & & $770 \mathrm{~Hz}$ (for 456 row) \\
& & & $852 \mathrm{~Hz}$ (for 789 row) \\
& & & $941 \mathrm{~Hz}$ (for *0\# row) \\
\hline
\end{tabular}

a)

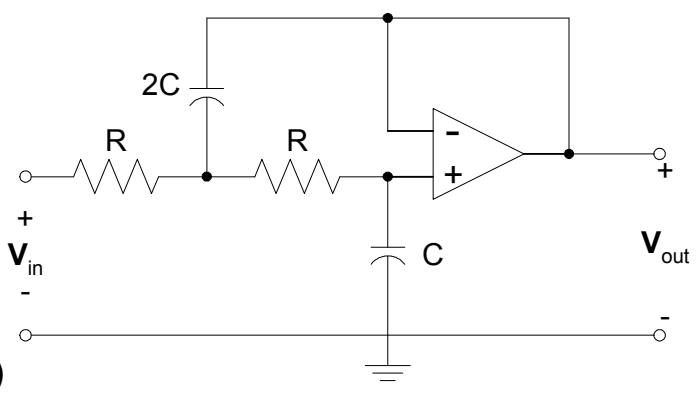

b)

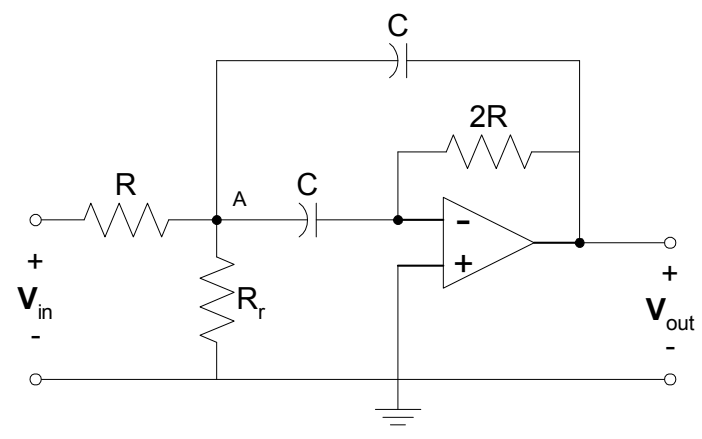

Figure 4: Circuits for implementation of (a) low-pass and (b) band-pass Butterworth filters. (Adapted from P. Horowitz and W. Hill, p. 274.) ( $^{3}$

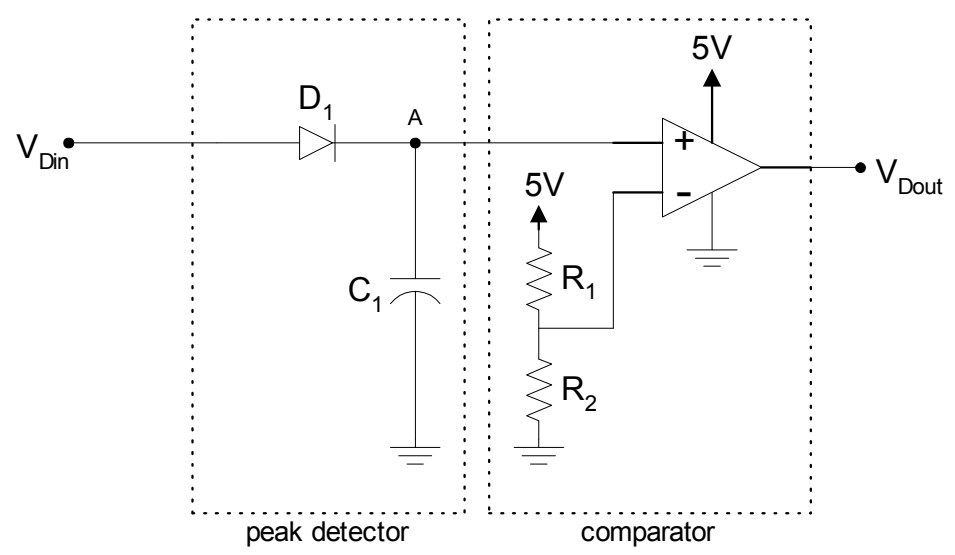

Figure 5: Detector sub-circuit for design project. (Adapted from P. Horowitz and W. Hill, pp. 217, 231. $)^{3}$ The students were given this circuit diagram and asked to select values for the resistors, build and test the sub-circuit. This was their first exposure to diodes. The students built the circuit using a 741 op-amp and a 1N4005 diode.

Proceedings of the 2004 American Society for Engineering Education Annual Conference \& Exposition Copyright (C2004, American Society of Engineering Education 
The design for the detector sub-circuit (Figure 5) was given to the students; however, they had to build and test the sub-circuit. The detector consists of two parts: a peak detector and a comparator. The detector sub-circuit was designed to create a logical high when the input to the detector exceeded $2.5 \mathrm{~V}$. The detector output was connected to a $5 \mathrm{~V}$ light emitting diode to provide a visual indicator of the detector response. The project was built in stages and then tested as a complete row detector. The students verified their designs first by testing with a function generator, and then by testing with a touch-tone keypad.

Integration with Course and with Curriculum

It has been observed that students enjoy laboratories more when they are connected together as a single project rather than a discrete set of unrelated exercises. ${ }^{4}$ This lab is designed to be the culminating laboratory exercise for the class, and it draws on several of the earlier exercises. The schedule for laboratory exercises during this module of the course is shown in Table 2. In particular, portions of the design project, such as the use of MATLAB and the design of an active, second-order, low-pass filter were introduced earlier into the semester. The other labs reinforce the connection between resonance and filtering.

Table 2: Summary of laboratory exercise schedule for frequency response module of course

\begin{tabular}{|c|c|}
\hline Week & Laboratory Exercise \\
\hline 1 & $\begin{array}{l}\text { Series Resonance: This is a hardware lab focused on passive filter circuit and the dependence of } \\
\text { resonance behavior on resistive and reactive components. Lab also reinforces hand-drawn Bode plots. }\end{array}$ \\
\hline 2 & $\begin{array}{l}\text { Active Filters: This is a hardware lab that compares two types of second-order low-pass filters - an } \\
\text { active Butterworth filter (Figure } 4 \text { a) and a filter formed by cascading single-stage active low-pass } \\
\text { filters. The Butterworth circuit is given with unit component values, and the students use scaling to } \\
\text { determine the proper component values to achieve the desired cut-off frequency. }\end{array}$ \\
\hline 3 & $\begin{array}{l}\text { Bode Plots with MATLAB: This lab introduces the students to the use of MATLAB for manipulating } \\
\text { transfer functions and creating Bode plots. }\end{array}$ \\
\hline 4 & $\begin{array}{l}\text { Underdamped, Critically Damped and Overdamped Responses: This lab requires the students to design a } \\
\text { parallel RLC circuit for a specific underdamped natural response, and then vary their design to create } \\
\text { circuits with a critically damped and an overdamped response. They verify their design by simulating the } \\
\text { circuits in PSPICE and comparing their behavior against the predicted behavior plotted in MATLAB. }\end{array}$ \\
\hline 5 & $\begin{array}{l}\text { RLC Transients: This hardware lab uses the same circuit as in the series resonance lab, only it now } \\
\text { focuses on transient responses. The resistance value is varied to create underdamped, critically damped } \\
\text { and overdamped responses. The lab required the students to solve for the expected behavior using } \\
\text { Laplace analysis. }\end{array}$ \\
\hline 6 & $\begin{array}{l}\text { Convolution with } M A T L A B \text { : This lab requires the students to apply convolution first to a pair of } \\
\text { equations, and then to use it to solve for the response of circuit to a sinusoidal pulse, similar to the } \\
\text { signal that will be an input to their telephone detector. }\end{array}$ \\
\hline 7,8 & Design Project \\
\hline
\end{tabular}

The project is also designed to connect this course with other courses in the electrical engineering curriculum. It introduces the students to MATLAB, which is used extensively in the upper level signals and DSP courses, ${ }^{5}$ and the digital output requirement ties it to the digital systems course that the students are taking concurrently. Furthermore, the project introduces students to a simple diode circuit (a peak detector), which prepares them for the material they will study the following semester in electronics. 
Summary

The project grade was determined by the successful demonstration of a circuit which met the design specifications and by an evaluation of the documentation and analysis of the project in the students' laboratory notebook. All of the student groups were able to build a functioning detector. The overall lab grade average for the students was a high $\mathrm{B}$, which was significantly higher than the overall course average, which was at the $\mathrm{B} / \mathrm{C}$ border. The students' comments in class and on anonymous questionnaires were very favorable for the design project and for the frequency response portion of the course.

We plan to expand the scope of this design project further during this academic year, by assigning groups to different rows and columns so as to assure complete coverage of the detectors required for the touchtone decoder system. We will then conclude the project by combining all of the student circuits with a digital logic circuit to display the numbers as they are dialed and identified.

\section{Acknowledgements}

The authors would like to thank the departmental technical support staff, in particular Jerry Ballman and Daphi Jobe, for their assistance with supporting the laboratories.

\section{Bibliography}

1. $\quad$ Edward, N.S., Preaching to the converted. Intl. J. Elec. Eng. Educ., 2002. 39(3): p. 230-238.

2. Alexander, C.K. and M.N.O. Sadiku, Fundamentals of Electric Circuits, $2^{\text {nd }}$ edition. 2004, Boston: McGraw-Hill Higher Education.

3. Horowitz, P. and W. Hill, The Art of Electronics. 1989, Cambridge: Cambridge University Press.

4. $\quad$ Evans, A., T. Davies, and S. Wilks, Is your laboratory a turn-off? Intl. J. Elec. Eng. Educ., 2002. 39(3): p. 284-292.

5. Wright, C.H.G., et al. Teaching DSP: bridging the gap from theory to real-time hardware. in Proceedings of the American Society for Engineering Education Annual Conference and Exposition. 2002.

SAMARA FIREBAUGH

Samara Firebaugh is an assistant professor at the U. S. Naval Academy, where she teaches and conducts research in the field of microelectromechanical systems. She received the B.S. degree from Princeton University in 1995 and the M.S. and Ph.D. degrees from the Massachusetts Institute of Technology in 1997 and 2001.

\section{BRIAN JENKINS}

Brian Jenkins received the B.S. and M.S. degrees from The Ohio State University in 1983 and 1991, and the Ph.D. degree from the University of Colorado in 1995. From 1983-1989 he worked as a development engineer for IBM Corporation in Endicott, New York. Since 1996 he has been a professor in the Department of Electrical Engineering at the U.S. Naval Academy where he teaches and does research in fiber optic communications. 


\section{JOHN CIEZKI}

John G. Ciezki is an Associate Professor of Electrical \& Computer Engineering at the United States Naval Academy. He recently joined USNA, following a nine-year tenure at the Naval Postgraduate School. He received his doctorate in electrical engineering from Purdue University in 1993. Over the past 14 years, he has been involved in various research projects and his sponsors have included NASA, NAVSEA, NSWC, ONR, and USMC. His research interests include the analysis, design, simulation, and control of electric machines, power converters, and drive systems. Specifically, his work seeks to develop technologies and design tools to support the deployment of more survivable and capable shipboard power and propulsion systems. 